\title{
BIOTECHNOLOGY IN THE CONSERVATION AND ENHANCEMENT OF PLANT GENETIC RESOURCES
}

P. GANASHAN

Plant Genetic Resources Centre, Peradeniya.

\section{Introduction}

Plant genetic diversity is the foundation upon which sustainable advances in agricultural productivity can be built and national food security ensured. Plant genetic resources form the backbone of dynamic, diverse and adaptable agriculture. The continuing success of releasing improved crop varieties for cultivation depends on the availability of a genetic resource base that is found in traditional varieties, landraces and their wild relatives. These genetic resources are threatened by the widespread adoption of genetically uniform crop varieties, pressure of population growth and desertification. Conserving these plant genetic resources for future use, therefore forms an important part of any viable crop development strategies. Research advances in plant biotechnology which permit the transfer of genes across species sexual barriers have further enhanced the agricultural, economic and social value of the plant genetic resources.

\section{Germplasm assemblage}

The diverse agro-ecology of Sri Lanka has sustained a rich genetic diversity of crop species, including those of wild relatives and related taxa. Collections of rice germplasm from the different regions of Sri Lanka were initiated in 1920, which resulted in pure-line selections for yield improvement. Collections of important germplasm of crop plants were maintained by the Department of Agriculture (DOA) for the use of plant breeders since its inception. Systematic collection of local varieties were made for rice and other major crops during mid 1970's. More comprehensive collection and conservation programmes were launched with the establishment of Plant Genetic Resources Centre (PGRC) in 1989 with assistance from Japan International Cooperation Agency (JICA).

\section{Role of PGRC}

PGRC has embarked on a very successful genetic resources management and research programme involving collection, introduction, evaluation, conservation and data management to strengthen the crop development activities of the DOA. Genetic conservation efforts are supported through studies being undertaken to understand genetic diversity parameters, distribution patterns, conservation biology, preservation technology, and mutidisciplinary evaluations to identify desirable gene sources in the assembled germplasm. 
Advances in biotechnology brought about by a combination of in vitro technology, genetics and molecular biology are rapidly changing the way agricultural scientists look at crop genepools and at crop improvement. Crop breeders are no longer confined to seeking genes useful for improvement among the closest relatives of the target genotype. In this context, PGRC is developing the research capability and capacity to undertake biotechnology research to support the germplasm conservation and development needs of the DOA.

\section{Biotechnology applications}

Plant biotechnology provides an opportunity for converting genetic diversity into economic and ecological assets through novel genetic combinations. In the present state of development, PGRC applies biotechnology tools in genetic resources conservation and enhancement. In this regard, the role of biotechnology is one of supporting the conventional technology applications as outlined in Table 1.

Table 1 : Integration of biotechnology in genetic resources activities

Genetic resources

Biotechnology applications

components

Acquisition

In vitro culture, disease indexing and eradication, (diversity measurements)

(in vitro collecting)

Multiplication

Micropropagation

Conservation

In vitro conservation, (detection of duplicates)

Evaluation

Enhancement

Isozymes, (RAPD)", (RFLP)",

Embryo rescue, callus culture,

somaclonal variation, (in vitro

mutagenesis and selection)

()* Programmes planned for the future

In vitro Conservation

In vitro conservation is undertaken at PGRC as a component of the genetic conservation complementing the field genebank system for clonally propagated crops and recalcitrant seed producing crops. This approach is being used to cut down on field maintenance costs and prevent loss through weather damage, pathogens and neglect in the field. The active in vitro genebank system using minimal growth conditions are currently operational. At present, two hundred and eighty one accessions covering seven crop species are being maintained (Table 2). Crop specific 
culture media have been perfected for conservation and regeneration of these crop species.

Table 2 : In Vitro Conservation Status

\begin{tabular}{lc}
\hline Crop & Accessions \\
\hline Cassava & 65 \\
Sweet potato & 70 \\
Potato & 130 \\
Colocasia spp. & 05 \\
Innala & 01 \\
Dioscorea & 05 \\
Banana & 05 \\
\hline Total & \\
\hline
\end{tabular}

Research on in vitro base collection using cryopreservation technology in which metabolic activities are arrested have already been initiated. Storage propagules used are shoot tips, buds and embryos of recalcitrant seeds. Methodologies for cooling, rewarming and liquid nitrogen sensitivity cryoprotection etc. are being studied for a range of crops. Protocols are being attempted for crops such as potato, pineapple and recalcitrant seed producers such as jak, citrus, etc. Viability of tissue or cell, genetic integrity, and ability to regenerate plants from the preserved material are prerequisites for the successful application of cryopreservation technique.

\section{Pathogen - free plantlets}

The bacterial and fungal pathogens are often eliminated by surface sterilization of the explant before placing it in culture.

Meristem culture technology is being widely applied in combination with thermotherapy (heat treatment), chemotherapy (chemical treatment) and antibiotics to facilitate the production of virus free plantlets. This technology is predominantly applied in vegetatively propagated species in which parental clones have become infected by a virus. The plantlets thus produced are used as planting materials and for germplasm exchange in compliance with the quarantine regulations.

Meristem tip culture has the additional advantage of maintaining the integrity of the original plant with minimal genetic variation. 


\section{Micropropagation}

Micropropagation is being used to produce a large number of planting material rapidly from pathogen free plantlets. Asexually propagated plants, or others with long generation times as trees could be propagated by using these techniques. Micropropagation techniques must be standardized for each species, varieties or cultivar differences within species as well. Protocols have been established through successful combination of explant source, culture media and culture conditions for a number of crops of agri-horticultural importance (Table 3). Successful shoot and root formation and field survival has been achieved in all these crops.

Table 3 : Crops for which micropropagation protocols are established

\begin{tabular}{ll}
\hline Crop & Explant used \\
\hline
\end{tabular}

Food

Potato

Shoot tips /

axillary buds

Sweet potato

Dioscorea

Innala

Colocasia

Fruits

Pineapple

Shoot tips/

Banana

axillary buds

Papaya

Avocado

Meristèms

Seedling

Buds

Medicinal

Niyangala

Meristems

Komarika

Meristems

Ornamental

Ferns

Meristems

In potato, the micropropagation programme has been enlarged to include production of tuberlets in vitro. However, the production cost of in vitro tuberlets is higher than that of in vitro plantlet. Studies are being conducted to increase the efficiency of tuber formation using chemicals which induce tuberization. In vitro produced tuberlets are used as material for the production of quality basic seeds. They are preferred to the plantlets as they survive longer in transit. 
Isozyme methods

Isozyme and protein electrophoresis are being used as a more direct study of the genome for supplementing morphological and agronomic evaluation of genetic diversity assembled at PGRC. Studies have been conducted using rice accessions to estimate genetic diversity in the germplasm assembled at PGRC. This methodology is also useful in genotype identification of advanced breeding lines.

\section{Germplasm enhancement}

Apart from the on-going research programme of in vitro germplasm conservation and micropropagation, the following biotechnological studies are carried out to support the DOA crop improvement efforts towards enhancing crop productivity: (a) Embryo rescue (b) Somaclonal variation (c) Anther culture (d) Induced in vitro mutagenesis (e) Non-traditional gene transfer.

\section{(a) Embryo rescue}

Following the sexually induced wide hybridization beyond the primary gene pool, tissue culture techniques are used to nurture the otherwise abortion-prone embryo. Various tissue culture techniques used in wide crosses include (a) in vitro pollination and fertilization, (b) fertilized ovule or ovary culture, and (c) hybrid embryo culture. In wide crosses the abortion-prone embryos are rescued from the maternal environment by aseptically removing and culturing them on an appropriate medium that allows for the development of intact and fertile plants.

Embryo rescue technology coupled with hormonal and pollination techniques developed for in vitro systems has led to the use of interspecific and intergeneric hybridization in crop breeding. Embryo rescue techniques have been used in rice crosses involving wild rice species (Onyza nivara, $O$. mizomatis, $O$. nufipogan, $O$. eichingeri) and the cultivated rice O.sativa.

The cross involving $O$. nivara $\times O$. sativa - variety $\mathrm{H}-4$ has yielded valuable hybrid materials. When cultivated rice is crossed with wild rice species the resulting embryo usually aborts after 14 days. These abortion prone embryos can be rescued by raising them under in vitro condition and can be induced to regenerate F-1 plants.

(b) Somaclonal variation

Phenotypic variations observed in plants regenerated from tissue culture are termed somaclonal variations. These variations may be morphological, physiological, qualitative and quantitative characteristics that show chromosomal, nuclear and cytoplasmic differences from the original plants.

Somaclonal variations which are genetically stable and heritable are passed on to the next generation, but the epigenetic variations disappear following sexual 
reproduction. The heritable somaclonal variations are of potential value to plant breeders and novel genotypes could be selected.

Variant cells or cell lines could be selected in vitro for their ability to grow in the presence of selective agents as herbicides, fungal filtrates, or high salinity which inhibit the growth of nonvariant and other susceptible cells. The cell culture should have spontaneous or induced mutations, and the resistance reaction must be active at the cellular level, to respond to this technique.

At the PGRC, somatic embryogenesis has been exploited in banana with a view to generate somaclonal variations. Potato and Innala tissue culture systems have been established to obtain somaclonal variants. Plants were regenerated from cultured leaf tissues of innala and core tissue of potato tubers. Studies on callus culture system and regeneration ability of indica rices are also in progress and encouraging results have been obtained (Table 4).

Table 4: Present Status of Callus culture and Plant Regeneration Studies

\begin{tabular}{|c|c|c|c|c|}
\hline Crop & Explant & $\begin{array}{l}\text { Callus } \\
\text { formation }\end{array}$ & $\begin{array}{l}\text { Root } \\
\text { formation }\end{array}$ & $\begin{array}{l}\text { Shoot } \\
\text { formation }\end{array}$ \\
\hline $\begin{array}{l}\text { Rice } \\
\text { Traditional } \\
\text { Improved } \\
\text { Japonica }\end{array}$ & $\begin{array}{c}\text { Embryo } \\
n \\
"\end{array}$ & $\begin{array}{c}\text { Successful } \\
"\end{array}$ & $\begin{array}{c}\text { Successful } \\
" \\
"\end{array}$ & $\begin{array}{c}\text { Partly successful } \\
" ~ \\
"\end{array}$ \\
\hline Innala & $\begin{array}{l}\text { Leaf tissue } \\
\text { Stem tissue }\end{array}$ & $"$ & $"$ & $\begin{array}{c}\text { Successful } \\
\end{array}$ \\
\hline Potato & $\begin{array}{l}\text { Tuber core } \\
\text { tissues }\end{array}$ & $"$ & $"$ & Partly successful \\
\hline Banana & Leaf petiole & $n$ & & Embroids \\
\hline Tomato & $\begin{array}{l}\text { Hypocotyl } \\
\text { tissues }\end{array}$ & $"$ & $"$ & No \\
\hline $\begin{array}{l}\text { Cassava } \\
\text { Sweet potato } \\
\text { Bird nest fern }\end{array}$ & $\begin{array}{l}\text { Stem tissues } \\
\text { Stem tissues } \\
\text { Leaf tissues }\end{array}$ & " & " & $\begin{array}{c}\text { No } \\
\text { No } \\
\text { Successful }\end{array}$ \\
\hline
\end{tabular}


(c) Induced in vitro mutagenesis

Induction of mutations using physical (gamma rays, neutrons) or chemical (alkylating agents) mutagens, and the use of improved selection technology have contributed significantly to the development of genotypes with desirable characteristics specially to be grown in stressed environments. Mutations are more often of the recessive type which will be difficult to detect in a diploid state. Combining anther culture technology with induced mutagenesis will be advantageous as the induced mutations can be detected immediately. Millions of haploid cells could be grown in a culture flask which offer a larger number of selectable units, and a system for introducing a screening agent. The isolated variant cell must be capable of regenerating into a plant and the mutated gene must be expressed at the whole plant level and transmitted stably to subsequent generations. Tolerance to environmental stresses as drought, salinity, etc. and to diseases could be attempted in this way.

At PGRC shoot tip cultures of pineapple were irradiated with gamma rays to obtain desirable mutants. About 50 percent of the cultures exposed to lower radiations produced phenotypic changes. In banana somatic embryogenesis has been successfully developed for genetic improvement using induced mutations followed by. somatic cell manipulations.

(d) Anther culture

Pollen mother cells are isolated from anthers and cultured to produce haploid plants, which can be screened rapidly for desirable traits. Anther culture has the potential to compress breeding cycles, increase selection efficiency, provide for early expression of recessive genes and expose gameto-clonal variants.

Haploid condition allows efficient selection as recessive alleles are not masked by dominant alleles. Haploid vegetative tissues can be used to isolate protoplast of different species/genera to be hybridized by somatic cell fusion. This results in diploid hybrid rather than polyploid hybrids derived from diploid somatic cell fusion. Haploids also provide a unique opportunity to study gene action and the effect of environment. Doubling the chromosomes of haploids results in homozygous true breeding lines which could be used to;

i) stabilize unique germplasm in homozygous form. This also has special benefits for rapid pureline fixation for tree crops and other economic species with long sexual cycles.

ii) produce inbred lines for hybrid production, and where possible identification and selection of male sterile types.

iii) fix gene combinations at the conclusion of a backcrossing programme. 
A programme to integrate biotechnology in conventional crop improvement programme is underway at PGRC in collaboration with the Central Rice Breeding Station (CRBS), Batalagoda. Anthers from japonica $\mathrm{x}$ indica, indica $\mathrm{x}$ indica hybrids are being used for the generation of haploid and spontaneous dihaploid plantlets at PGRC. Seeds of these anther derived doubled haploid F1 plants are being grown at CRBS, Batalagoda for necessary field screening and adoption as breeding lines for yield testing.

(e) Non-traditional methods of gene transfer

Genetical transformation of plants, across sexual reproduction has greatly extended the gene pool available to crop breeders. Gene transfer is aided by protoplast fusion, use of bacterial or viral vectors, and direct gene transfer through microinjection or electroporation. These technologies require increasing amounts of scientific expertise, time, and financial resources when one progresses from simpler biotechnologies to modern ones (Figure 1).

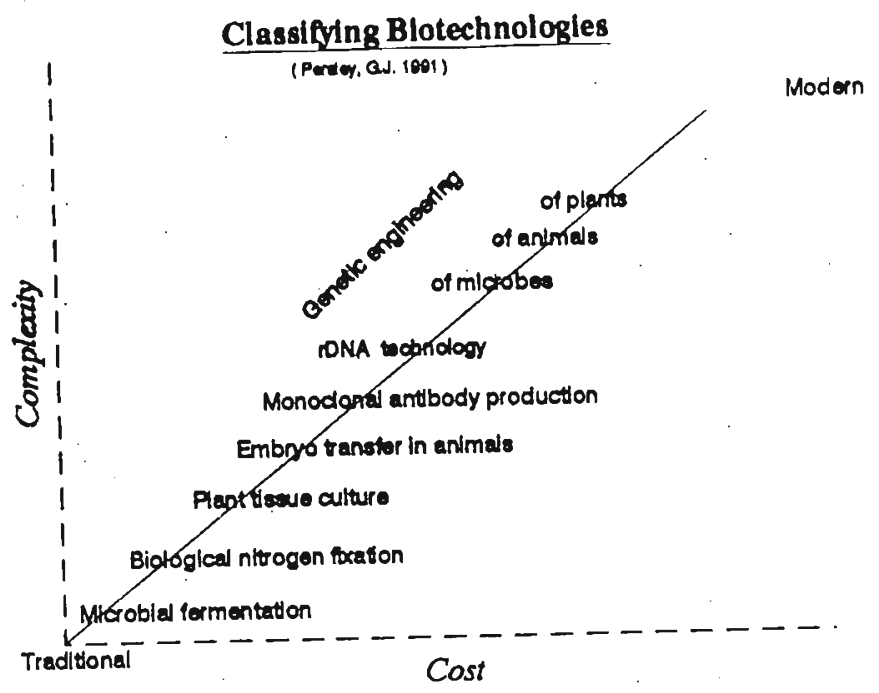

Figure 1

\section{Somatic hybridization}

Somatic cell hybridization by protoplast technology overcomes sexual incompatibility barriers and allowes hybridization between any two plants irrespective of their taxonomic relationship. The naked plasma membrane of the protoplast allows entry of foreign DNA, cell organelles, bacteria or virus particles. Genomic hybrids, cytoplasmic hybrids and partial hybrids with some chromosomes eliminated results from somatic cell fusion. 
Thus protoplast fusion creates a novel cytoplasmic mix in which organelles of both plants come together in a common cytoplasmic milieu. This technique provides opportunities to investigate cybridization through cytoplasmic transfer. Fusions may be carried out electrically or using polyethylene glycol possessing low carbonyl content. Protoplast fusion resulting in cytoplasmic mix, offers the opportunity of producing cybrids and for creating mitochondrial and chloroplast recombinants. Transfer of cytoplasmic male sterility, organelle genome manipulation, cytoplasmic mixing, and basic studies on heterosis, gene expression, chromosome elimination, organelle fusion, and recombination are possible areas for exploitation.

Studies are in progress at the University of Nottingham, U.K. to increase the tolerance of rice to salt through protoplast fusion of the salt tolerant wild relative Porteresia coarctata with a cultivated rice variety.

\section{Recombinant - DNA technology}

Recombinant-DNA technology often referred to as genetic engineering, involves the transfer of genetic material (DNA) from a cell of one species to another unrelated species, and made to express itself in the recipient cells. This technology provides the opportunity for the interchange of genes of plant, animal, bacterial, fungal or viral origin, and offers an unlimited gene pool for genetic enhancement. Even chemically synthesized genes can be transferred to develop transgenic plants.

The major components in the recombinant - DNA technology are:

(a) Gene identification and isolation for transfer

(b) Delivery systems to introduce the desired genes into the recipient cells. The introduction of foreign genetic material into plant cells is either with the use of bacterial or viral vectors or through direct introduction of DNA with the aid of microinjection or electroporation.

(c) Expression of the new genetic information in the recipient cells. Some research areas that contribute to this are:gene sequencing, gene cloning, development of gene vectors, chromosome micromanipulations, gene integration, control of gene expression, gene stability and transmission, and organelle transfer. The soil bacteria Agrobacterium tumefaciens which causes crown gall, and $A$. rhizogenes, which is responsible for hairy root diseases in dicotyledonous plants, and some viruses can act as vectors and mediate transfer of genetic material into plants. Genes for resistance to herbicides and pests have been successfully transferred in other countries through Agrobacterium vector to important crop plants, vegetables and ornamental plants. Direct gene transfer is useful in monocots where Agrobacterium is generally not effective as vector. Gene transfer using micro-injection involves the transfer of DNA solution under pressure into plant protoplasts using micro-pipettes.

Substantial contributions have been made by recombinant-DNA technology in genetic enhancement of crop plants, although it lags far behind the prokaryote and 
animal research areas. A current limitation is the lack of efficient transformation and regeneration systems especially for cereals. Transgenics in more than 40 crop plants including rice, maize, soybean, tomato and potato have been developed overseas, but they are yet to be used commercially.

For these gene transfers, genetic markers like Restriction Fragment Length Polymorphism (RFLP) or Randomly Amplified Polymorphic DNA (RAPD) need to be used to map characteristics on the chromosomes. This is important for the identification of genes responsible for tolerance to environmental stresses and resistance to diseases. With the perfection of the transformation technology, biotechnologists and molecular breeders can rely on gene bank accessions as valuable sources for genes to be isolated, cloned and transferred. A genetic map of rice chromosomes holding over 1000 RFLP markers has been developed at the National Institute of Agrobiological Resources, Japan, and Cornell University, U.S.A.

\section{Significance in genetic improvement}

The crop plants of today had their origins in the fields of primitive hunters/gatherers who first developed agriculture by bringing plants into cultivation for food. With increase in population, genotypes of crop plants with greater adaptability to the climatic and edaphic conditions have been selected for cultivation, to ensure greater and safer supplies of food. The methodology of hybridization was developed to combine desirable characteristics of many plants in one plant to enhance productivity and other desirable characteristics. Induced mutation technology has further enhanced the varietal improvement programmes.

The impact of varietal improvement programme has been witnessed in the green revolution in the major cereal food crops-wheat, rice and maize. However the effect of biotechnology could be felt potentially in all crops-cereals, pulses, oil seeds, root and tubers, vegetables, fruits, spices etc., which affected all nations, all locations, including marginal lands affected by drought, salinity, aluminium toxicity, etc. In addition to conventional plant breeding skills, biotechnology requires molecular and cell biology expertise. Biotechnology approaches will not be taken to replace traditional plant breeding, but will complement it. It will be used to solve problems for which conventional methodologies have limited scope; and where biotechnology can yield fruitful results.

\section{Conclusion}

Biotechnology is emerging as a powerful tool to support plant genetic resources activities. It has applications in the utilization of plant genetic resources through mass propagation in vitro, in genetic mainpulations, in the safe transfer of germplasm, in phytopathology, in characterization and in in vitro conservation of germplasm to support the benefits arising from other applications. For achieving such goals it is necessary to establish a national pool of expertise in tissue culture, molecular biology and genetic engineering. Emphasis must be given to the development of a knowledge base and for identifying priority areas of biotechnology applications. 